\title{
TINGKAT RISIKO KEJADIAN KARDIOVASKULAR PADA PENYANDANG DIABETES MELITUS TIPE 2
}

\author{
Fiska Nur Aini ${ }^{1}$, Anggi Lukman Wicaksana ${ }^{2,3 *}$, Heny Suseani Pangastuti ${ }^{2}$ \\ ${ }^{1}$ Program Studi Ilmu Keperawatan, Fakultas Kedokteran, Kesehatan Masyarakat, dan Keperawatan, \\ Universitas Gadjah Mada, Yogyakarta, 55281, Indonesia \\ ${ }^{2}$ Departemen Keperawatan Medikal Bedah, Fakultas Kedokteran, Kesehatan Masyarakat, dan \\ Keperawatan, Universitas Gadjah Mada, Yogyakarta, 55281, Indonesia \\ ${ }^{3}$ The Sleman Health Demographic and Surveillance System, Fakultas Kedokteran, Kesehatan \\ Masyarakat, dan Keperawatan, Universitas Gadjah Mada, Yogyakarta, 55281, Indonesia \\ *)E-mail: anggi.l.wicaksana@ugm.ac.id
}

\begin{abstract}
ABSTRAK
Individu dengan diabetes melitus tipe 2 memiliki risiko dua hingga tiga kali lipat terjadinya risiko kejadian kardiovaskular, yaitu serangan jantung atau stroke. Organisasi kesehatan dunia dan masyarakat international hipertensi mengembangkan alat untuk memprediksi tingkat risiko kejadian kardiovaskular dalam kurun waktu sepuluh tahun yang akan datang. Tujuan: Penelitian bertujuan untuk mengetahui tingkatan risiko kardiovaskular pada penyandang diabetes tipe 2 dalam sepuluh tahun mendatang di Yogyakarta. Metode: Penelitian cross-sectional dilakukan di Puskesmas Depok, Yogyakarta dengan menggunakan teknik proportional sampling pada tiga Puskesmas Depok. Responden penelitian yaitu pasien terdiagnosis diabetes tipe 2, berusia 40-79 tahun, dan tidak memiliki komplikasi atau penyakit lain. Instrumen yang digunakan yaitu WHO/ISH risk prediction charts wilayah Indonesia (SEAR B) untuk menilai tingkatan risiko kejadian kardiovaskular. Data diklasifikasikan berdasarkan tingkat risiko kejadian kardiovaskuler yang dimiliki. Data dianalisis secara univariat. Hasil: Sejumlah 66 responden terlibat dengan mayoritas responden adalah perempuan, tidak bekerja, menikah dan rerata usia 61,02 $\pm 8,86$. Tingkat risiko kejadian kardiovaskular penyandang diabetes tipe 2 di Puskesmas Depok, Yogyakarta dalam kurun waktu sepuluh tahun mendatang yaitu risiko rendah 56,1\%; risiko sedang 30,3\%; risiko tinggi 9,1\%; dan risiko sangat tinggi 4,5\%. Lebih dari separuh responden memiliki risiko rendah $(<10 \%)$ terkena serangan jantung atau stroke dalam waktu sepuluh tahun mendatang. Selain itu, satu dari tiga responden memiliki risiko sedang (10-20\%) terjadi serangan jantung atau stroke. Kesimpulan: Separuh dari responden penyandang diabetes memiliki risiko non-fatal kejadian kardiovaskular.
\end{abstract}

Kata Kunci: diabetes tipe 2, penyakit kardiovaskular, insiden

\section{Risk Level of Cardiovascular Event Among Type 2 Diabetes Mellitus}

\section{ABSTRACT}

Individuals with type 2 diabetes have two to three times risk of cardiovascular event, as heart and stroke attack. World Health Organization and International Society of Hypertension had developed a prediction method of the risk level of cardiovascular event for the following ten years. Objective: This study aimed to identify the risk level of cardiovascular event over the next ten years on people with type 2 diabetes in Yogyakarta. Method: The study used a cross-sectional design in three Public Health Centers Depok, Yogyakarta using proportional sampling technique. The respondents were patients diagnosed with type 2 diabetes, age of 40-79 years, and no comorbidity. The WHO/ISH risk prediction charts for diabetes population in Indonesian (SEAR B) was used to assess the risk level of cardiovascular event. Data was analyzed with univariae analysis. Results: A total of 66 respondents were recruited after reviewing eligibility criteria. The majority of the respondents were women, unemployed, married, and the average age was 61.02 \pm 8.86. The risk levels of cardiovascular event among participants in the next ten years were gradually low risk (56.1\%); moderate risk (30.3\%); high risk (9.1\%); and very high risk (4.5\%). More than a half of participants had low risk or less than $10 \%$ 
for being cardiovascular event in the following ten years. Furthermore, one third of participants had moderate risk or 10-20\% developing cardiac arrest or stroke attack. Conclusion: A half of diabetes participants had non-fatal risk of cardiovascular event.

Keywords: type 2 diabetes, cardiovascular disease, incidence

\section{LATAR BELAKANG}

Diabetes melitus (DM) merupakan salah satu penyakit tidak menular yang mengalami peningkatan prevalensi secara global (WHO/World Health Organization, 2011; Walker dkk, 2017) Pada tahun 2017 terdapat 425 juta jiwa terkena diabetes melitus dan diperkirakan pada tahun 2045 mengalami peningkatan menjadi 629 juta jiwa (IDF/ International Diabetes foundation, 2017). Di Indonesia, pada tahun 2013 terdapat 12 juta penduduk Indonesia usia $\geq 15$ tahun menyandang DM. Individu yang terdiagnosis diabetes di Provinsi Daerah Istimewa Yogyakarta sebesar 3,0\% dan menduduki urutan tiga teratas prevalensi diabetes di Indonesia (Kementrian Kesehatan RI, 2013).

DM tipe 2 merupakan tipe diabetes yang paling banyak terjadi yaitu sebesar 88\% (NHS/National Health Service, 2013). DM tipe 2 dapat memengaruhi berbagai sistem organ dalam tubuh, sehingga dapat menyebabkan komplikasi (Chawla, Chawla, \& Jaggi, 2017). Komplikasi dari DM diklasifikasikan menjadi komplikasi mikrovaskular seperti neuropati dan nefropati, serta komplikasi makrovaskular termasuk stroke dan serangan jantung (Bartels, Davidson, \& Gong, 2007; Chawla, Chawla, \& Jaggi, 2017).

Terjadinya ketidakseimbangan gula darah akan menyebabkan kerusakan pembuluh darah besar maupun kecil dan dapat meningkatkan agregat platelet dimana dua kondisi tersebut akan menyebabkan aterosklerosis, peningkatan viskositas darah kemudian akan meningkatkan tekanan darah yang berakibat stroke atau gangguan di jantung (Ueshima, dkk, 2008). Penelitian menunjukkan bahwa penyandang
DM memiliki risiko serangan jantung dan stroke dua hingga tiga kali lipat lebih tinggi dibandingkan individu yang tidak mengalami DM (Kozakova \& Polombo, 2016). Kemungkinan terjadinya serangan jantung atau stroke dikenal dengan risiko kejadian kardiovaskular. Kejadian kardiovaskular menjadi salah satu komplikasi yang paling sering terjadi pada penyandang diabetes (IDF, 2017).

Tingginya prevalensi DM tipe 2 secara global serta bahaya komplikasi diabetes tipe 2, sehingga diperlukan upaya deteksi dini mengetahui risiko yang dimiliki. World Health Organization (WHO) dan International Society of Hypertension (ISH) mengembangkan diagram prediksi risiko untuk memprediksikan tingkat risiko kejadian kardiovaskular dalam kurun waktu sepuluh tahun yang akan datang (WHO, 2007). Pemahaman risiko kejadian kardiovaskular pada penyandang diabetes penting guna mengetahui upaya pencegahan dan pengendalian kejadian kardiovaskular secara lebih awal. Prediksi tingkat risiko kardiovaskular cukup sederhana sehingga dapat dilakukan di fasilitas kesehatan tingkat pertama ataupun layanan rumah sakit (WHO, 2007; Wicaksana, dkk, 2017).

Pada tahun 2017 penemuan kasus diabetes di Kecamatan Depok, Yogyakarta menjadi yang tertinggi di Kabupaten Sleman (Sleman HDSS/Health and Demographic Surveilance System, 2017). Hasil studi pendahuluan yang dilakukan, didapatkan data kunjungan penyandang diabetes melitus tipe 2 di Puskesmas Depok sebanyak 431 setiap bulannya. Oleh karena itu, menjadi hal penting untuk mengetahui tingkatan risiko kardiovaskular 
pada penyandang diabetes di wilayah ini sebagai gambaran sebaran risiko kejadian kardiovaskular dalam kurun waktu sepuluh tahun mendatang.

\section{METODE PENELITIAN}

Penelitian ini merupakan penelitian deskriptif dengan rancangan cross-sectional study. Penelitian dilakukan di Puskesmas Depok I, II, dan III, Sleman, Yogyakarta selama 10 bulan dan pengambilan data dilakukan pada bulan Oktober-November 2018. Populasi pada penelitian ini adalah penyandang diabetes tipe 2 di Puskesmas
Setelah ditentukan proporsi jumlah sampel pada setiap Puskesmas, peneliti menggunakan teknik consecutive sampling dengan kriteria inklusi: (1) penyandang DM tipe 2, (2) usia responden 40-79 tahun, (3) terdaftar sebagai peserta prolanis, dan (4) bersedia mengikuti penelitian. Kriteria eksklusi ditetapkan: (1) pasien dengan gangguan jiwa divalidasi dengan rekam medis, dan (2) penyandang DM tipe 2 dengan penyakit penyerta lainnya.

Instrumen yang digunakan dalam penelitian ini adalah WHO/ISH risk prediction chart untuk Indonesia (SEAR B). Risiko

Tabel 1. Proporsi jumlah sampel di Puskesmas Depok I, II, dan III pada tahun 2017

Nama Puskesmas $\begin{gathered}\text { Jumlah penyandang } \\ \text { diabetes tipe } 2\end{gathered}$

Depok I

Depok II

Depok III

Total
1.423

1.600

2.147

5170
Proporsi

Jumlah sampel yang diambil
Depok I, II, dan III Sleman, Yogyakarta. Penentuan besar sampel penelitian deskriptif menggunakan rumus Lemeshow (Dahlan, 2016) sehingga didapatkan besar sampel yaitu 66 responden dengan estimasi responden mengalami dropout sebesar $10 \%$. Teknik sampling pada penelitian ini adalah proportional sampling berdasarkan perbandingan jumlah penyandang diabetes melitus tipe 2 dengan total jumlah penyandang diabetes melitus tipe 2 di tiap Puskesmas. kejadian kardiovaskular ditentukan oleh peneliti (FNA) berdasarkan indikator usia, jenis kelamin, status merokok, ada tidaknya diabetes, kolesterol total dan tekanan darah sistolik dengan menggunakan diagram prediksi risiko dari WHO/ISH. Hasil prediksi risiko akan mendapatkan satu warna diagram dari lima pilihan tingkatan risiko; hijau, kuning, jingga, merah dan merah gelap (WHO, 2007; Wicaksana dkk, 2017). Hasil interpretasi risiko kejadian fatal dan non-fatal kardiovaskular pada sepuluh tahun mendatang menurut WHO adalah sebagai 
berikut: (1) warna hijau, yaitu risiko $<10 \%$ atau risiko rendah, (2) warna kuning, yaitu risiko $10 \%$ sampai $20 \%$ atau risiko sedang, (3) warna jingga, yaitu risiko $20 \%$ sampai < $30 \%$ atau risiko tinggi, (4) warna merah, yaitu risiko $30 \%$ sampai $<40 \%$ dan warna merah gelap risiko $>40 \%$, untuk risiko sangat tinggi (Gambar 1).

Penelitian ini telah mendapatkan perizinan kelaikan etik penelitian dari Komite Etik Penelitian Kedokteran dan Kesehatan Fakultas Kedokteran, Kesehatan Masyarakat, dan Keperawatan Universitas Gadjah Mada - RSUP. Dr. Sardjito dan mendapatkan ijin dari dinas terkait. Responden yang bersedia terlibat diminta untuk menandatangani informed consent. Peneliti mengumpulkan data demografi dengan wawancara, melakukan pemeriksaan tekanan darah dengan sphygmomanometer (ABN Compact $®$, PT. Sugih Instrumendo Abadi) setelah istirahat minimal 10 menit dan menggukur kolesterol dengan pemeriksaan darah tepi menggunakan alat pemeriksa kolesterol darah (GCU Easy Touch $囚)$ tanpa puasa.

Analisis data menggunakan analisis univariat dengan menggambarkan tingkat risiko kejadian kardiovaskular dan tingkatan risiko berdasarkan karakteristik demografi di Puskesmas Depok I, II, dan III, Sleman, Yogyakarta. Data diolah menggunakan program komputer yaitu SPSS versi 20 dan data disajikan dalam bentuk tabel distribusi frekuensi.

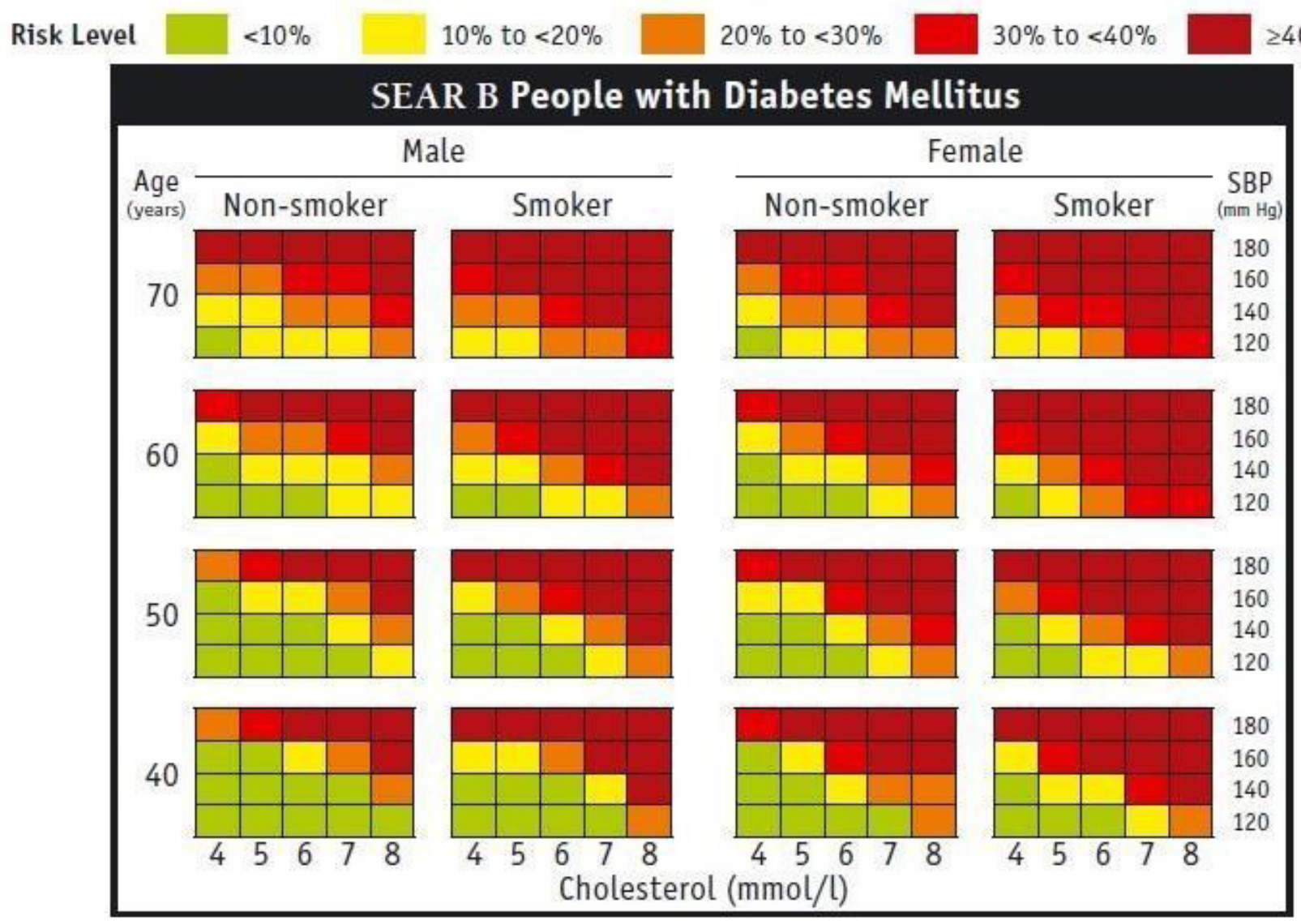

Gambar 1. WHO/ISH risk prediction chart untuk penyandang diabetes di Indonesia 
HASIL

Sejumlah 69 calon responden diminta terlibat, tiga responden menolak dengan alasan sibuk dan tidak ada waktu. Sehingga total responden yang terlibat dalan penelitian adalah 66 orang, dan telah memenuhi standar perhitungan sampel. Responden pada penelitian paling banyak adalah perempuan yaitu $77,3 \%$ dengan rerata usia
Hasil didapatkan bahwa penyandang diabetes melitus tipe 2 di Puskesmas Depok, lebih dari separuh memiliki risiko rendah terkena kejadian kardiovaskular pada sepuluh tahun yang akan datang yaitu sebesar 56,1\% (Tabel 2), namun secara bertahap terjadi degradasi untuk tingkat risiko sedang, tinggi, dan sangat tinggi.

\section{Tabel 2. Tingkat risiko kejadian kardiovaskular penyandang DM di Puskesmas Depok $(n=66)$}

\begin{tabular}{lcc}
\hline \multicolumn{1}{c}{ Tingkat Risiko Kejadian Kardiovaskular } & Frekuensi & $\begin{array}{c}\text { Persentase } \\
\mathbf{( \% )}\end{array}$ \\
\hline Risiko Rendah $(<10 \%)$ & 37 & $56,1 \%$ \\
Risiko Sedang $(10 \%-<20 \%)$ & 20 & $30,3 \%$ \\
Risiko Tinggi $(20 \%-<30 \%)$ & 6 & $9,1 \%$ \\
Risiko Sangat Tinggi $(\geq 30 \%)$ & 3 & $4,5 \%$ \\
\hline
\end{tabular}

responden yaitu $61,02 \pm 9,71$ tahun. Rerata tekanan darah sistolik responden yaitu $130,39 \pm 9,71 \mathrm{mmHg}$ dan tekanan darah diastolik yaitu $80,65 \pm 8,07 \mathrm{mmHg}$. Tingkat pendidikan responden paling banyak pada tingkat Sekolah Menengah Atas (SMA) yaitu $31,8 \%$. Sebanyak $71,2 \%$ responden berstatus tidak bekerja, berstatus menikah sebesar $72,7 \%$, dan $62,1 \%$ responden tidak memiliki riwayat keluarga dengan DM, dan $97 \%$ responden tidak merokok.
Tingkat risiko kardiovaskular berdasarkan karakteristik demografi dapat dilihat pada Tabel 3. Pada tingkat risiko rendah kardiovaskular terjadi paling banyak pada kelompok usia 60-69 tahun. Tingkat risiko kejadian kardiovaskular pada perempuan cenderung lebih tinggi daripada laki-laki. Responden dengan status tidak merokok, tidak bekerja, menikah, tidak memiliki riwayat keluarga dengan diabetes dan dislipidemia mendominasi karakterikstik demografi responden. 
Tabel 3. Distribusi tingkat risiko kejadian kardiovaskular berdasarkan karakteristik demografi di Puskesmas Depok $(n=66)$

\begin{tabular}{|c|c|c|c|c|c|}
\hline \multirow{2}{*}{ Variabel } & \multicolumn{4}{|c|}{ Tingkat Risiko Kardiovaskular (n, \%) } & \multirow[t]{2}{*}{ Total } \\
\hline & Rendah & Sedang & Tinggi & $\begin{array}{c}\text { Sangat } \\
\text { Tinggi }\end{array}$ & \\
\hline \multicolumn{6}{|l|}{ Usia } \\
\hline $40-49$ & $7(10,6 \%)$ & $1(1,5 \%)$ & $0(0 \%)$ & $0(0 \%)$ & $8(12,1 \%)$ \\
\hline $50-59$ & $12(18,2 \%)$ & $5(7,6 \%)$ & $2(3 \%)$ & $1(1,5 \%)$ & $20(30,3 \%)$ \\
\hline $60-69$ & $17(25,8 \%)$ & $7(10,6 \%)$ & $2(3 \%)$ & $2(3 \%)$ & $28(42,4 \%)$ \\
\hline $70-79$ & $1(1,5 \%)$ & $7(10,6 \%)$ & $2(3 \%)$ & $0(0 \%)$ & $10(15,2 \%)$ \\
\hline \multicolumn{6}{|l|}{ Jenis Kelamin } \\
\hline Laki-laki & $9(13,6 \%)$ & $4(6,1 \%)$ & $2(3 \%)$ & $0(0 \%)$ & $15(22,7 \%)$ \\
\hline Perempuan & $28(42,4 \%)$ & $16(24,2 \%)$ & $4(6,1 \%)$ & $3(4,5 \%)$ & $51(77,3 \%)$ \\
\hline \multicolumn{6}{|l|}{ Pendidikan } \\
\hline Tidak sekolah & $2(3 \%)$ & $3(4,6 \%)$ & $0(0 \%)$ & $0(0 \%)$ & $5(7,6 \%)$ \\
\hline SD & $8(12,1 \%)$ & $6(9,1 \%)$ & $1(1,5 \%)$ & $2(3 \%)$ & $17(25,8 \%)$ \\
\hline SMP & $6(9,1 \%)$ & $3(4,5 \%)$ & $2(3 \%)$ & $0(0 \%)$ & $11(16,7 \%)$ \\
\hline SMA & $13(18,7 \%)$ & $5(7,6 \%)$ & $2(3 \%)$ & $1(1,5 \%)$ & $21(16,7 \%)$ \\
\hline Sarjana/Diploma & $8(12,1 \%)$ & $3(4,5 \%)$ & $1(1,5 \%)$ & $0(0 \%)$ & $12(18,2 \%)$ \\
\hline
\end{tabular}




\begin{tabular}{|c|c|c|c|c|c|}
\hline \multirow[b]{2}{*}{ Variabel } & \multicolumn{4}{|c|}{ Tingkat Risiko Kardiovaskular (n, \%) } & \multirow[t]{2}{*}{ Total } \\
\hline & Rendah & Sedang & Tinggi & $\begin{array}{l}\text { Sangat } \\
\text { Tinggi }\end{array}$ & \\
\hline
\end{tabular}

\section{Pekerjaan}

Bekerja $\quad 13(19,7 \%) \quad 6(9,1 \%) \quad 0(0 \%) \quad 0(0 \%) \quad 19(28,8 \%)$

Tidak bekerja $\quad 24(36,4 \%) \quad 14(21,2 \%) \quad 6(9,1 \%) \quad 3(4,5 \%) \quad 47(71,2 \%)$

Perkawinan

Menikah

$32(48,5 \%) \quad 11(16,7 \%) \quad 3(4,5 \%) \quad 2(3 \%)$

$48(72,7 \%)$

Duda/Janda

$5(7,6 \%)$

$9(13,6 \%) \quad 3(4,5 \%)$

$1(1,5 \%)$

$18(27,3 \%)$

Riwayat Keluarga dengan diabetes melitus

Ya

$16(24,2 \%) \quad 6(9,1 \%) \quad 2(3 \%)$

$1(1,5 \%) \quad 25(37,9 \%)$

Tidak

$21(31,8 \%)$

$14(21,2 \%) \quad 4(6,1 \%)$

$2(3 \%)$

$41(62,1 \%)$

\section{Merokok}

$\begin{array}{lllll}\text { Ya } & 2(3 \%) & 0(0 \%) & 0(0 \%) & 0(0 \%)\end{array}$

Tidak

$35(53 \%)$

$20(30,3 \%) \quad 6(9,1 \%)$

$3(4,5 \%)$

$64(97 \%)$

\section{Dislipidemia}

Ya

$15(22,7 \%)$

$17(25,8 \%) \quad 6(9,1 \%)$

$3(4,5 \%)$

$41(62,1 \%)$

Tidak

$22(33,3 \%) \quad 3(4,5 \%) \quad 0(0 \%)$

$0(0 \%)$

$25(37,9 \%)$ 


\section{DISKUSI}

Risiko kejadian kardiovaskular adalah seberapa jauh penyandang DM tipe 2 akan mengalami serangan stroke atau serangan jantung pada sepuluh tahun yang akan datang (WHO, 2007; Wicaksana dkk, 2017). Risiko ini termasuk bagian dari komplikasi makrovaskuler diabetes. Hasil penelitian didapatkan $56,2 \%$ responden memiliki risiko rendah. Hal ini berarti lebih dari separuh responden memiliki tingkat risiko kejadian kardiovaskular $<10 \%$ terkena serangan stroke atau jantung dalam kurun waktu sepuluh tahun mendatang (WHO, 2007). Responden yang berada pada tingkat risiko rendah bukan berarti tidak memiliki risiko kardiovaskular (Wicaksana dkk, 2017; Savitharani dkk, 2019). Kelompok ini masih memiliki risiko meski tidak fatal untuk berkembang menjadi stroke atau serangan jantung. Rekomendasi yang diberikan pada kelompok risiko rendah berfokus pada menjaga gaya hidup sehat (Wicaksana dkk, 2017).

Meththananda, dkk (2015) melaporkan bahwa sebanyak $78,5 \%$ responden memiliki tingkat risiko rendah serangan jantung dan stroke, senada dengan temuan penelitian. Hal tersebut terjadi karena responden tidak memiliki penyakit penyerta sebagai komorbiditi. Selain itu, responden merupakan anggota program pengelolaan penyakit kronis (Prolanis) diabetes yang mana diketahui rutin melakukan pengobatan. Pengobatan diperlukan secara rutin untuk mengendalikan kadar gula darah, tekanan darah, lipid dan berat badan, sehingga dapat mencegah timbulnya komplikasi (SosaRubi, Galárraga, \& López-Ridaura, 2009). Kegiatan Prolanis juga terdapat edukasi diabetes untuk memberikan informasi kepada peserta dengan tujuan untuk mengubah perilaku maladaptif sehingga dapat menurunkan tingkat risiko kejadian kardiovaskular (BPJS, 2014). Pengobatan serta kontrol rutin merupakan salah satu pilar utama pengelolaan diabetes untuk menurunkan risiko kejadian kardiovaskular.

Sepertiga dari seluruh responden memiliki tingkat risiko sedang atau sebesar $10-<20 \%$. Hal tersebut berarti responden memiliki risiko terkena serangan stroke dan jantung dalam kurun waktu sepuluh tahun mendatang yang lebih besar dua kali dibandingkan dengan responden yang memiliki risiko rendah (Wicaksana dkk, 2017). Kelompok dengan risiko sedang diminta untuk menjalankan gaya hidup sehat dengan tambahan pemantauan faktor risiko (kolesterol, SBP, merokok) dan pemantau risiko tiap 6-12 bulan sekali (WHO, 2007; Wicaksana dkk, 2017).

Satu dari sepuluh dan satu dari dua puluh responden memiliki risiko tinggi dan sangat tinggi, secara berurutan. Risiko tinggi berarti responden memiliki kemungkinan terjadi serangan sebesar $20-<30 \%$ sementara risiko sangat tinggi berarti berpotensi serangan dengan probabilitas $\geq 30 \%$. Kedua kelompok ini perlu perhatian khusus agar mampu menurunkan tingkat risiko yang dimiliki dan mengendalikan faktor risiko yang ada. Rekomendasi yang perlu dilakukan adalah serupa dengan kelompok risiko sedang ditambah pemantau tingkat risiko tiap 3-6 bulan dan beberapa memerlukan obat-obatan untuk penyakit kardiovaskular (WHO, 2007).

Hasil dari penelitian ini usia yang paling banyak memiliki risiko terjadinya serangan stroke maupun serangan jantung yaitu usia 60-69 tahun (42,4\%). Hal tersebut konsisten dengan penelitian yang dilakukan di Puskesmas Mlati, Sleman, Yogyakarta pada populasi pasien dengan penyakit kardiovaskular dengan hasil pada risiko rendah usia yang paling banyak adalah pada usia 60-69 tahun (Septiani, Sunaryo, \& Wicaksana, 2018). Hal tersebut karena terjadi perubahan fisiologis pada lansia 
(Fillit, Rockwood, \& Young, 2016). Usia lanjut merupakan salah satu faktor risiko untuk perkembangan penyakit kardiovaskular karena telah terpapar oleh berbagai faktor risiko lain seperti merokok atau terpapar asap rokok, hipertensi, dan dislipidemia (Norhammar \& Schenck-Gustafsson, 2013).

Hasil penelitian ini didapatkan distribusi tingkat risiko responden perempuan $(77,3 \%)$ lebih tinggi dibandingkan dengan lakilaki $(22,7 \%)$. Hasil ini konsisten dengan penelitian yang dilakukan pada populasi pasien dengan penyakit kardiovaskular di Puskesmas Mlati I dan II, Sleman, Yogyakarta bahwa tingkat risiko rendah ditemukan jumlah responden perempuan $(66,67 \%)$ lebih tinggi dibandingkan dengan laki-laki (33,33\%) (Septiani, Sunaryo, \& Wicaksana, 2018). Hasil tersebut karena jumlah responden sebagian besar berjenis kelamin perempuan. Selain itu, ketika perempuan memasuki usia menopause, maka terjadi peningkatan kadar kolesterol darah total dan low density lipoprotein sehingga akan meningkatkan risiko kardiovaskular (Aquarista, 2017).

Pada penelitian ini didapatkan sebesar $97 \%$ responden berstatus tidak merokok atau telah berhenti merokok minimal satu tahun dan memiliki risiko rendah kardiovaskular. Risiko terkena penyakit jantung koroner pada perokok dapat berkurang sebesar $50 \%$ setelah berhenti merokok selama satu tahun (Karini \& Padmawati, 2018). Hal tersebut karena responden sebagian besar berjenis kelamin perempuan. Selain itu, budaya Jawa menganggap perempuan perokok adalah perbuatan yang menyimpang dan tidak baik sehingga jarang ditemukan perempuan Jawa merokok (Meshram dkk, 2016). Sebanyak $62,1 \%$ responden pada penelitian ini mengalami dislipidemia. Hal ini karena mayoritas responden memiliki kadar kolesterol darah total yang tinggi dengan rerata $223,84 \mathrm{mg} / \mathrm{dL}$. Individu dengan
DM tipe 2 akan mengalami dislipidemia meskipun telah mengontrol kadar gula darah dengan baik (Lastra dkk, 2014).

Paling banyak responden yang memiliki tingkat risiko adalah responden dengan status tidak bekerja yaitu sebesar $71,2 \%$. Hal tersebut sejalan dengan penelitian yang dilakukan di Puskesmas Mlati, Yogyakarta bahwa responden yang memiliki tingkat risiko rendah kardiovaskular paling banyak adalah responden dengan status tidak bekerja $(66,67 \%)$ (Septiani, Sunaryo, \& Wicaksana, 2018). Hal tersebut karena sebagian responden telah memasuki masa pensiun, dibuktikan dengan data yang menyatakan bahwa usia produktif seseorang untuk bekerja yaitu pada usia 15-59 tahun (BPJS/Badan Penyelenggara Jaminan Sosial, 2014). Selain itu, sebagian besar responden berjenis kelamin perempuan dan menjadi ibu rumah tangga.

Paling banyak responden yang memiliki tingkat risiko adalah responden dengan status menikah $(72,7 \%)$. Sejalan dengan penelitian yang dilakukan di Puskesmas Mlati bahwa respoden yang memiliki tingkat risiko kardiovaskular paling banyak pada responden dengan status menikah $(85,19 \%)$ (Septiani, Sunaryo, \& Wicaksana, 2018). Hal ini sesuai dengan data yang menyatakan bahwa rerata usia kawin pertama laki-laki sebesar 25,7 tahun dan perempuan 22,3 tahun (BPS/Badan Pusat Statistik, 2018). Respoden dalam penelitian berusia antara 40-79 tahun sehingga sebagian besar ditemukan dalam kondisi telah menikah dan mimiliki pasangan.

\section{SIMPULAN}

Tingkat risiko kardiovaskular diukur menggunakan $\mathrm{WHO} / \mathrm{ISH}$ risk prediction chart. Lebih dari separuh responden memiliki risiko rendah dalam kurun waktu sepuluh tahun mendatang. Tingkat risiko rendah lebih banyak ditemukan pada kelompok usia 
60-69 tahun, berjenis kelamin perempuan, tidak bekerja, menikah, tidak merokok dan mengalami dislipidemia.

Saran yang dapat diberikan yaitu peserta Prolanis diabetes sebaiknya tetap rutin untuk mengikuti kegiatan Prolanis di Puskesmas. Meskipun mayoritas responden memiliki risiko rendah, hampir separuh responden $(43,9 \%)$ memiliki tingkat risiko sedang hingga sangat tinggi. Hal ini perlu mendapatkan tindakan khusus untuk pemantauan berkala dan upaya penurunan faktor risiko. Tindakan pencegahan juga diperlukan pada kelompok ini sehingga tidak terjadi komplikasi lain yang dapat berakibat fatal. Penelitian serupa perlu dikembangkan dengan besar sampel lebih besar serta memperluaskan cakupan wilayah penelitian. Peneliti lanjutan dengan membandingkan responden DM tanpa dan dengan komplikasi perlu dilakukan untuk melihat sebaran tingkat risiko kejadian kardiovaskular secara lebih detail.

\section{UCAPAN TERIMA KASIH}

Rasa terima kasih peneliti ucapkan kepada Fakultas Kedokteran, Kesehatan Masyarakat, dan KeperawatanUniversitas Gadjah Mada selaku penyandang dana penelitian payung tahun 2018 . Terima kasih juga peneliti ucapkan kepada tim penelitian Diabetes and Cardiovascular Care gen 2 yang telah memberikan saran dan masukan untuk peneliti. Terima kasih kepada peserta Prolanis Puskesmas Depok I, II, III yang telah berpartisipasi dalam penelitian ini.

\section{DAFTAR PUSTAKA}

Aquarista, N. C. (2017). Perbedaan Karakteristik Penderita Diabetes Melitus Tipe 2 Dengan dan Tanpa Penyakit Jantung Koroner. Jurnal Berkala Epidemiologi, 5(1): 37-47.

Bartels, D. W., Davidson, M. H., \& Gong, W. C. (2007). Type 2 diabetes and cardiovascular disease: reducing the risk. Journal of Managed Care Pharmacy, 13(2 Supp A): 1-17.

BPJS. PROLANIS (Program Pengelolaan Penyakit Kronis). Retrieved from https://bpjs-kesehatan.go.id/bpjs/ dmdocuments/06-PROLANIS.pdf.

BPS. (2018). Sensus Penduduk 2010: Umur Penduduk. Retrieved from https:// sp2010.bps.go.id/

Chawla, A., Chawla, R., \& Jaggi, S. (2016). Microvasular and macrovascular complications in diabetes mellitus: distinct or continuum? Indian Journal of Endocrinology and Metabolism, 20(4): 546-551.

Dahlan, M. S. (2006). Besar sampel dalam penelitian kedokteran dan kesehatan. Jakarta: PT Arkans.

Fillit, H. M., Rockwood, K., \& Young, J. B. (2016). Brocklehurst's Textbook of Geriatric Medicine and Gerontology E-Book. Elsevier Health Sciences. Retrieved from https://www.sciencedirect. com/book/9781416062318/ brocklehursts-textbook-of-geriatricmedicine-and-geron tology

Health Demographic Surveillance System Sleman. (2017). Penyakit tidak Menular [Brochure]. Sleman, Daerah Istimewa Yogyakarta.

IDF. (2017). IDF diabetes atlas eighth edition 2017. London: IDF.

Karini, T. A., \& Padmawati, R. S. (2018). Fenomena sosial unik pada perokok wanita di kabupaten Lebong Bengkulu Indonesia. Berita Kedokteran Masyarakat, 34(1): 1924.

Kementrian Kesehatan RI (2013). Riset kesehatan dasar (Riskesdas). Laporan Hasil Riset Kesehatan Dasar. Jakarta: Kementian Kesehatan RI.

Kozakova, M., \& Palombo, C. (2016). Diabetes mellitus, Arterialwall, and car- 
diovascular risk assessment. International Journal of Environmental Research and Public Health, 13(2, 201):1-14.

Lastra, G., Syed, S., Kurukulasuriya, L. R., Manrique, C., \& Sowers, J. R. (2014). Type 2 diabetes mellitus and hypertension: an update. Endocrinology and Metabolism Clinics, 43(1): 103-122.

Meshram, A., Kachhawa, K., Gujar, V., \& Bokariya, P. (2016). Correlation of dyslipidemia and type 2 diabetes mellitus amongst the people of Vidarbha region of India. IOSRPHR, 6(1): 45-50.

Meththananda, H., Priyantha, T., Weeraranthna, Umesha, D. (2015) Cardiovascular risk assessment type 2 diabetes mellitus: comparison of the world health organization / international society of hypertension risk prediction charts versus UK prospective diabetes study risk. DovePress Journal: Vascular Health and Risk Management, 11: 583-589.

NHS. (2013). National Health Service Standard Contract. Retrieved from https://www.gov.uk/government/ news/38-million-people-in-englandnow-have-diabetes.

Norhammar, A., \& Schenck-Gustafsson, K. (2013). Type 2 diabetes and cardiovascular disease in women. Diabetologia, 56(1): 1-9.

Savitharani, B. B., Madhu, B., Renuka, M., \& Ashok, N. C. (2016). Utilization of WHO-ISH 10-year CVD risk prediction chart as a screening tool among supporting staff of a tertiary care hospital, Mysuru, India. Heart India, 4(1): 13-16.

Septiani, V. E., Sunaryo, E. Y. A. B., Wicaksana, A. L. (2018). Gambaran Tingkat Risiko Penyakit Kardiovaskular di Wilayah Kerja Puskesmas Mlati Sleman Yogyakarta (Skripsi). Universitas Gadjah Mada, Yogyakarta, Indonesia.

Sosa-Rubí, S. G., Galárraga, O., \& LópezRidaura, R. (2009). Diabetes treatment and control: the effect of public health insurance for the poor in Mexico. Bulletin of the World Health Organization, 87: 512-519.

Ueshima, H., Sekikawa, A., Miura, K., Turin, T. C., Takashima, N., Kita, Y., .. \& Nakamura, Y. (2008). Cardiovascular disease and risk factors in Asia: a selected review. Circulation, 118(25): 27022709.

Walker, I. F., Garbe, F., Wright, J., Newell, I., Athiraman, N., Khan, N., \& Elsey, H. (2018). The economic costs of cardiovascular disease, diabetes mellitus, and associated complications in South Asia: a systematic review. Value in Health Regional Issues, 15: 12-26.

WHO. (2007). Prevention of Cardiovascular Disease: Pocket Guidelines for Assessment and Management of Cardiovascular Risk. Geneva: WHO.

WHO. (2011). Global Atlas on Cardiovascular Disease Prevention and Control. Geneva: WHO.

Wicaksana A, Septiani V, Artawan IPA, Jumayanti, Destiana AK, Lulu L. (2017). Pedoman Pengkajian dan Pengelolaan Risiko Kardiovaskular - versi Bahasa Indonesia [https:// www.researchgate.net]. Retrieved from https://www.researchgate.net/ publication/321330134_Pedoman Pengkajian_dan_Pengelolaan_ Risiko_Kardiovaskular_-_versi_ Bahasa_Indonesia/ 